\title{
Descontinuidades e ressurgências: entre o normal e o patológico na teoria do controle social
}

\author{
Discontinuities and reappearances: between the normal \\ and the pathological in the theory of social control
}

Francis Moraes de Almeida

Professor do Programa de Pósgraduação em Ciências Sociais/ Universidade Federal de Santa Maria.

Avenida Roraima, 1000, prédio 74, sala 2205

Cidade Universitária - Camobi 97105-900 - Santa Maria - RS Brasil

framses@gmail.com
ALMEIDA, Francis Moraes de. Descontinuidades e ressurgências: entre o normal e o patológico na teoria do controle social. História, Ciências, Saúde - Manguinhos, Rio de Janeiro, v.20, n.3, jul.-set. 2013, p.1057-1078.

Resumo

Procura-se apontar ambiguidades e lacunas da distinção entre patologia e normalidade nos âmbitos social e individual que remontam a fins do século XIX e ressurgem de outra maneira contemporaneamente. Nas últimas décadas do século XIX, muitos autores aderiram à teoria da criminalidade atávica defendida pela antropologia criminal italiana, liderada por Lombroso. A chamada escola francesa critica o determinismo biológico italiano, seguindo por outra via, deixando a cargo das ciências 'psi' o que considera a dimensão individual da criminalidade. Aproveitando esse espaço a psiquiatria cria o 'psicopata', herdeiro do 'criminoso nato' em vários aspectos e aceito contemporaneamente como categoria psicopatológica. Nesse contexto, o estudo tem como foco o controle social envolvendo a distinção entre patologia e normalidade nos planos social e individual.

Palavras-chave: normalidade; patologia; psicopatia; sociologia.

\section{Abstract}

This text highlights ambiguities and gaps in the distinction between pathology and normality in the social and individual ambits dating back to the late nineteenth century and reemerging in another guise in contemporary times. In the last decades of the nineteenth century, many authors adopted the theory of atavic criminality defended by Italian criminal anthropologists led by Lombroso. The French school criticized Italian biological determinism and left to the 'psi' sciences the aspects it deemed to be the individual dimension of criminality. Taking advantage of this space, psychiatry created the 'psychopath', inheritor in many ways of the 'innate criminal', and today accepted as a psychopathological category. In this context, the article focuses on social control involving the distinction between pathology and normality in the social and individual spheres.

Keywords: normality; pathology; psychopathy; sociology. 
$\mathrm{O}$ objetivo deste artigo é investigar as descontinuidades e ressurgências do debate sobre patologia e normalidade nas ciências sociais. Tal objetivo não implica qualquer tom acusatório ou juízo valorativo quanto aos conceitos considerados, como geralmente pode-se observar nos trabalhos tradicionais sobre história das ciências biológicas, tais como o de Ernst Mayr (1998). Sendo assim, não se trata de mostrar o conceito de patologia social como um anacronismo científico ou o considerar exclusivamente uma manifestação de tecnologias de poder específicas aos saberes médico ou jurídico, embora posições nesse sentido sejam frequentemente encontradas em trabalhos com uma orientação epistemológica similar à adotada aqui.

O conceito de patologia social nas ciências sociais não costuma ser empregado explicitamente de modo sistemático ao menos desde meados da década de 1970. Tal conceito remonta à tradição do organicismo sociológico francês, muito influente desde as contribuições de Comte, criando um efeito de reverberação que chegou, embora bastante mitigado, até os escritos de Durkheim. As preocupações desse expoente da sociologia francesa com o estatuto epistêmico da sociologia o levaram a se distanciar dos vícios metodológicos não científicos de antecessores (Bacon, Comte, Mill) e de contemporâneos, em sua maioria tão afeitos às metáforas biológicas para a explicação da vida social quanto ele (como Spencer).

Apesar do evidente desprestígio da 'patologia social', bem como do organicismo como corrente teórica desde fins do século XIX, ainda se observa o emprego de expressões que remontam a essa concepção da 'sociedade como organismo'. Como sugere Howard Becker (2007, p.65), esse tipo de artifício teórico costuma ser empregado mais como uma "representação científica", um quadro de pré-noções que orienta o pensamento científico, mesmo que de modo implícito. ${ }^{1}$

A partir da tradição francesa do estudo sobre a história das ciências, iniciada com Gaston Bachelard (1884-1962), passando por Georges Canguilhem (1904-1995) e Michel Foucault (1926-1984), as últimas reminiscências do triunfalismo científico vitoriano desmoronaram. Esforços nesse sentido permitiam aos mais otimistas, geralmente os próprios cientistas, como Julian Huxley (1887-1975), descrever a história dos 'avanços científicos' como prova de que a humanidade tendia inequivocamente ao progresso sob o baluarte da razão (Huxley, 1941, p.141). Nesse sentido, devem-se considerar simultaneamente as descontinuidades históricas e as ressurgências dos conceitos em determinada ciência, o que significa fazer mais do que a história da formação de uma teoria (medicina, biologia, sociologia etc.), também a história da formação do conceito, seguindo a sugestão de François Delaporte (1994, p.28): "é fazendo a história do conceito que podemos afirmar que uma mitologia e uma metáfora podem contribuir para a formação da ciência e, ao mesmo tempo, dela serem excluídas". O conceito de patologia social é assim entendido, simultaneamente, como condição de possibilidade para a delimitação de certos problemas, como objeto para a sociologia e como obstáculo a ser superado pela própria sociologia, uma vez que se reporta à metáfora do organicismo e à mitologia do progresso irrevogável da sociedade que acompanham as primeiras proposições da sociologia como um campo científico autônomo.

De fato, a descontinuidade é constitutiva na história de qualquer sistema de pensamento, embora não opere apenas por rupturas irreversíveis, mas também por retornos insuspeitos, consequências não premeditadas e reviravoltas por vezes paradoxais. ${ }^{2}$ 


\section{Comte e a medicina social}

Auguste Comte (1798-1857) foi o primeiro a propor o estudo da sociedade como uma ciência, mobilizado pelo desejo de libertar o pensamento humano tanto das quimeras teológicas quanto das seduções metafísicas que se emaranhavam nos escritos sobre a sociedade no início do século XIX. Sua pretensão estava epistemologicamente alicerçada no prestígio das ciências biológicas francesas. Serenadas as últimas convulsões da Revolução Francesa, sua intenção não era apenas descrever a realidade social, mas sim conhecer as leis sociais para melhor conduzir seus processos de mudança rumo ao almejado progresso (Coelho, 2005, p.66-67). A imagem da sociedade como um organismo está explicitada em vários momentos de sua obra ${ }^{3}$, e parece justificar a tendência à estabilidade que ele identifica como a norma nos processos sociais. Sendo assim, a distinção entre os processos socialmente normais e patológicos é fundamental para que a 'física social' - designação inicial da ciência posteriormente batizada 'sociologia' por Comte - possa orientar adequadamente a sociedade para o progresso (Benoit, 1999, p.325).

Tanto o progresso histórico geral da sociedade quanto cada manifestação particular desta deveriam ser concebidos segundo a sucessão das suas fases evolutivas, sintetizadas no famoso postulado da lei dos três estágios (teológico, metafísico e positivo), que constitui o eixo do pensamento social comtiano. Partindo dessa 'lei', baseada nas fases de desenvolvimento dos organismos segundo a fisiologia francesa da época, o autor concebe o seu projeto de reforma social sustentado na necessidade da manutenção da 'ordem' do organismo social para permitir o seu 'progresso', desde a 'infância' do espírito humano (estágio teológico) até sua maturidade (estágio positivo). Para Comte, a lei dos três estágios é um princípio de ordenação da realidade empírica válido também no âmbito das ideias. A decorrência lógica disso é a necessidade de uma classificação hierárquica das ciências (Coelho, 2005, p.17), das mais simples para as mais complexas: matemática, astronomia, física, química, biologia (na qual estavam compreendidas a patologia e a fisiologia) e, por fim, a física social ou sociologia (Comte, 1830). A proximidade de fisiologia e física social decorria de um vínculo epistemológico. Segundo Comte (1972, p.129): "para se ter um esboço completo do verdadeiro papel da fisiologia na física social que ... sendo o desenvolvimento da espécie apenas o resultante dos desenvolvimentos individuais que se encadeiam de uma geração a outra, deve apresentar, necessariamente, traços gerais de conformidade com a história natural do indivíduo". Deve-se destacar que essa analogia entre fisiologia e física social mostra que a diferença entre o organismo biológico individual e a sociedade é apenas de grau de complexidade, não de natureza. Esse é um dado importante para se compreender de que modo Comte concebe os fenômenos normais e patológicos tanto no âmbito individual quanto no social.

Comte inicia a publicação de seu Curso de filosofia positiva a partir de 1830, e logo a discussão sobre normalidade e patologia passa a ocupar lugar de destaque em seu sistema teórico. Vejamos que sentidos Comte atribui a esses conceitos.

Em O normal e o patológico (2006), publicado originalmente em 1943, Georges Canguilhem apresenta os dois conceitos, por um lado, como referentes a estados distintos qualitativamente, cada qual com uma natureza própria; por outro lado, como distintos apenas quantitativamente, representando uma mesma natureza que varia apenas em grau. Canguilhem vê Comte como 
um dos mais influentes defensores desse segundo preceito, que estabelece uma relação de homogeneidade e continuidade entre os conceitos de normalidade e patologia. O chamado 'princípio de Broussais', que Comte eleva ao estatuto de axioma geral, define que todas as doenças consistem "no excesso ou falta de excitação dos diversos tecidos abaixo ou acima do grau que constitui o estado normal" (Canguilhem, 2006, p.17).

Embora o princípio de Broussais implique logicamente a necessidade de quantificação, esse autor se restringe a apresentar alguns casos nos quais o princípio mostra-se válido, sem elencar meios para medir a variação de grau que distingue o normal do patológico ${ }^{4}$, o que o leva a qualificar os estados de excesso (mais do que os de falta) de nocivos, portanto, patológicos. A recomendação terapêutica era a redução de estímulos como purgante, sangria, dieta, frio etc. (Canguilhem, 2006, p.29).

Analogamente, Comte não define critérios para a delimitação do limiar da normalidade, afirmando que ela implica a "harmonia de influências distintas, tanto externas quanto internas" (Comte, citado em Canguilhem, 2006, p.22). Ou seja, a normalidade parece corresponder a uma ambígua noção de equilíbrio, e é sobre ela que Comte constitui a analogia entre fisiologia, patologia e física social no Curso de filosofia positiva. O que significa dizer que Comte realiza uma apropriação 'ideológica' do modelo biológico a seu sistema politico de pensamento. ${ }^{5}$ O emprego da metáfora organicista leva Comte a postular que é dever do físico social (ou sociólogo) 'medicar' o organismo social sempre que preciso, o que significa "reconduzi-lo ao seu estado normal" (Carrion, 1977, p.38). Para Comte, as ocorrências patológicas eram aquelas que permitiam melhor conhecer os estados normais, tanto no âmbito do organismo individual como do social. É nesse sentido que o princípio de Broussais permite conceber estados socialmente patológicos, as revoluções, por exemplo, como distintos apenas em grau da almejada normalidade. Canguilhem apresenta esse argumento nos seguintes termos:

Afirmando de maneira geral que as doenças não alteram os processos vitais, Comte se justifica por ter afirmado que a terapêutica das crises políticas consiste em trazer as sociedades de volta à sua estrutura essencial e permanente, em só tolerar o progresso nos limites de variação da ordem natural definitiva pela estática social. Portanto, na doutrina positivista, o princípio de Broussais limita-se apenas a uma ideia subordinada a um sistema, e foram os médicos, os psicólogos e os literatos de inspiração e tradição positivista que a difundiram como concepção independente (Canguilhem, 2006, p.32).

Embora a sociologia comtiana possa ser veemente criticada quanto a sua fragilidade epistemológica ou mesmo quanto aos deslizes teológicos de seu principal autor ao fim de sua vida, ela apresenta uma grande consistência política. Comte assimila preceitos de outros campos do saber, como o referido princípio de Broussais, e os adapta ao seu sistema político, sempre visando à constituição de sua idealizada sociedade governada por cientistas, estável politicamente e orientada pelo progresso (Comte, 1972, p.78). Sem dúvida, provém de Comte a representação mais influente da 'sociedade como um organismo', e suas reflexões sobre normalidade e patologia são o fundamento do desenvolvimento do conceito de patologia social como autêntica ideologia científica (Canguilhem, 1977). 


\section{Durkheim: a sociologia, o normal e o patológico}

Assim como a tradição sociológica reconhece em Auguste Comte o seu principal idealizador, cabe a Émile Durkheim (1858-1917) o mérito de ter delimitado a sociologia enquanto campo autônomo do conhecimento. Durkheim procura evitar os deslizes metodológicos de seu antecessor, bem como enfrentar as fragilidades epistemológicas da sociologia, embora, assim como Comte, esteja preocupado com a preservação de estabilidade social e procure encontrar meios para a intervenção em instituições sociais potencialmente entrópicas. ${ }^{6}$

No último decênio do século XIX, Durkheim enfrenta o desafio de definir um campo epistêmico próprio à sociologia, partindo de seu objeto específico, o 'fato social'. Essa tarefa é empreendida mormente em As regras do método sociológico (1983), publicado originalmente em 1895, cujos principais alvos são os pensadores sociais influentes e prestigiados por suas obras 'sociológicas', sobretudo Spencer e Tarde. Embora Durkheim se contraponha a cada um deles por motivos distintos, pode-se afirmar que o ponto comum em suas críticas é o fato de ambos adotarem a analogia entre indivíduo e sociedade já estabelecida por Comte.

Herbert Spencer (1820-1903) foi um pensador vitoriano por excelência, portanto avesso a qualquer especialismo. Sua obra versa principalmente sobre sociologia, psicologia e biologia, mas ele não se furta a considerações sobre política, economia e filosofia, com reflexões sempre marcadas por um evolucionismo social de caráter 'progressista' pelo qual se tornou conhecido (Boudon, Bourricaud, 2004). Spencer foi um dos principais defensores do uso da analogia organicista para a representação da sociedade. Segundo ele, a analogia entre o organismo individual e a sociedade podia ser observada tanto no crescimento contínuo apresentado por toda sociedade (característica de todos os organismos) quanto em sua progressiva especialização de funções (como a dos órgãos no organismo individual) representada pela divisão do trabalho (Spencer, 1877, p.466-470). Essa analogia explícita aliada ao grande prestígio das teorias de Spencer na França levaram Durkheim a criticá-lo em muitas passagens de suas obras, buscando claramente a hegemonia intelectual no âmbito da sociologia francesa, como aponta Mucchielli (2001, p.46-47).

Mesmo sendo um autor relevante, Spencer não era o principal alvo de Durkheim, pois no último decênio do século XIX seu prestígio já esmorecia, e havia adversários mais imediatos, como Gabriel Tarde (1843-1904), então o autor mais influente da sociologia francesa. Embora não tenha formado escola ou discípulos, Tarde fez franca oposição à sociologia durkheimiana (Muchielli, 2001, p.42; Consolim, 2008, p.270). Para Durkheim (1983) a 'teoria da imitação' defendida por Tarde (1890) era equivocada por manter a analogia entre psiquismo individual e coletivo estabelecida desde Comte, o que se tornava mais evidente nos textos em que procurava explicar manifestações criminosas coletivas, descritas como uma das mais evidentes expressões de comportamento imitativo (Tarde, 1992).

Apesar de ter empregado explicitamente a analogia organicista em "Da divisão do trabalho social" (2004) ${ }^{7}$, Durkheim evita citar contemporâneos organicistas para se mostrar distante dessa corrente de pensamento, inconciliável com sua proposta sociológica, apesar de suas semelhanças, conforme apontado por Barberis (2003). As principais preocupações sociais dos organicistas franceses eram similares às já demonstradas por Comte e, em sua maior parte, 
compartilhadas com Durkheim: o combate às chamadas patologias sociais ${ }^{8}$ ou situações 'socialmente anômicas' na conceituação durkheimiana.

No capítulo terceiro de As regras do método sociológico, intitulado "Regras para a distinção entre o normal e o patológico", Durkheim enfrenta a relação entre patologias individuais e o que seus contemporâneos denominavam 'patologia social' - embora ele evite empregar esse conceito, substituindo-o pelo de 'anomia' - e esclarece que sua intenção é cumprir a tarefa deixada incompleta por Comte - definir um critério científico para a distinção entre normalidade e patologia, tanto em termos individuais quanto sociais.

Com efeito, para as sociedades como para os indivíduos, sendo a saúde boa e desejável, é a doença, ao contrário, algo de ruim que deve ser evitado. Se, então, encontramos um critério objetivo, inerente aos próprios fatos, que nos permita, nas diversas ordens de fenômenos sociais, distinguir cientificamente a saúde da doença, a ciência será capaz de esclarecer a prática, muito embora se conservando fiel ao método que lhe é próprio (Durkheim, 1983, p.49). ${ }^{9}$

Ainda que Durkheim explicite que o estado normal é preferível ao da doença, ele rompe com Comte ao considerar a norma estatística o critério para a definição da normalidade social, identificada com aquilo que se observa mais frequentemente em determinada sociedade: "O que o fisiologista estuda são as funções do organismo médio, e o sociólogo faz o mesmo. Sendo possível distinguir uma das outras as espécies sociais - questão de que trataremos mais adiante - é sempre possível descobrir qual a forma mais geral que apresenta um fenômeno numa espécie determinada" (Durkheim, 1983, p.48-49).

Segundo Lukes (2005, p.47), ao aplicar esta distinção entre normalidade e patologia, Durkheim tendia a julgar as sociedades que considerava integradas mais estáveis do que realmente eram e a considerar desvios patológicos da sociedade francesa de então aquilo que não condizia com seu modelo de normalidade social. Conquanto a interpretação de Lukes não esteja incorreta, o que ele imputa a Durkheim são vícios comuns aos pensadores sociais de seu tempo. De um lado, a tendência a enfatizar excessivamente a integração e o rigor das 'sanções penais' nas sociedades selvagens será objeto de crítica de Malinowski (2008) a Durkheim e aos evolucionistas. De outro lado, a sobrevalorização das mazelas sociais no fin-de-siècle, especialmente a crença no aumento galopante das taxas de criminalidade, era tão geral quanto errônea entre os cientistas sociais da época, como ressalta McDonald (1982).

O caráter polêmico da proposta de Durkheim reside no exemplo utilizado por ele para demonstrar a distinção entre normal e patológico: o crime como fato social. O autor define que a ocorrência de crimes é normal em todas as sociedades humanas, desde que sua frequência não ultrapasse determinados níveis. Diz mais Durkheim (1983, p.58): “Classificar o crime entre os fenômenos de sociologia normal não é apenas dizer que constitui fenômeno inevitável, embora lastimável e devido à maldade incorrigível dos homens; é afirmar que é um fator de saúde pública, uma parte integrante de toda sociedade sã". Embora deva ser ressaltado que o mérito da definição do crime como fenômeno social normal seja de Adolphe Quetelet (17961874), o modo como Durkheim emprega essa tese em 1895 tem um caráter propositalmente polêmico, que merece destaque. ${ }^{10}$ Um de seus efeitos imediatos foi a reação de repúdio de 
Tarde, que criticou Durkheim por fatalismo e apologia ao crime (Pinheiro Filho, Machado, 2005), reação compartilhada por diversos autores fora da França. ${ }^{11}$

Mesmo que tenha confrontado abertamente os sociólogos franceses, Durkheim foi cauteloso em não bater de frente com a então ainda prestigiada antropologia criminal italiana, duramente atacada por Tarde: "Pelo fato de o crime ser um fenômeno de sociologia normal, não se deve concluir que o criminoso seja um indivíduo normalmente constituído do ponto de vista biológico e psicológico. As duas questões são independentes uma da outra. Compreenderse-á melhor esta independência quando tivermos mostrado mais adiante a diferença existente entre os fatos psíquicos e os fatos sociológicos" (Durkheim, 1983, p.58). Nessa perspectiva, o crime é sociologicamente normal, mesmo que o criminoso seja psicologicamente anormal ou patológico, como defendiam Lombroso, Ferri e Garofalo.

Em decorrência das duras críticas recebidas, Durkheim demonstra sua tese da normalidade social, fenômeno à época considerado decorrência exclusiva de condições patológicas individuais. Em O suicídio (1993), Durkheim alcança seu intento de apresentar a sociologia como uma ciência autônoma, dotada de métodos próprios, que ele demonstra ao empregar dados epidemiológicos da prevalência do suicídio em diversos países europeus e constituir uma explicação sociológica para a oscilação de suas frequências, bem como uma tipologia consistente para o que classifica como tipos de suicídio. Em síntese, ele consegue apresentar o suicídio como fato socialmente determinado, e como socialmente determinadas inclusive as próprias condições patológicas individuais (especialmente a melancolia) que, em alguns casos, pareciam ter levado ao ato suicida.

Com base na distinção durkheimiana entre normalidade e patologia social, estados anômicos como o que a França de então enfrentava (por definição, transitórios e patológicos), especialmente as altas taxas de criminalidade e suicídios, deveriam ser considerados problemas a ser enfrentados 'socialmente' pelos governantes, amparados pelos sociólogos. Evidencia-se nisso uma semelhança nada casual com o papel atribuído aos cientistas no modelo de reforma social comtiano, ainda mais ressaltado na passagem final do referido capítulo de Durkheim (1983, p.74-75): “O dever do homem de Estado não é mais empurrar violentamente as sociedades para um ideal que lhe parece sedutor, mas seu papel é o do médico: por meio de uma boa higiene, previne a eclosão das doenças, e, quando elas se declaram, procura saná-las".

Durkheim alcançou o seu intento, criou uma escola sociológica francesa com grande influência no século XX, tanto sobre a antropologia britânica e francesa quanto sobre a sociologia norte-americana. Entretanto, esse reconhecimento do domínio epistêmico próprio aos fenômenos sociais teve como efeito o distanciamento, por várias décadas, do interesse sociológico por condutas desviantes ou criminais que sugerissem uma anormalidade ou patologia de ordem individual, domínio à época ainda muito marcado por teorias biologicamente deterministas com as da antropologia criminal italiana.

\section{Dos criminosos atávicos aos psicopatas}

A sociologia francesa, de Comte a Durkheim, a despeito das diferenças entre esses autores e das evidentes descontinuidades entre suas obras, mantém um ímpeto reformista à medida que procura identificar certos fenômenos socialmente 'patológicos' e desenvolver meios 
para remediá-los. Em âmbito diverso, logo batizado criminologia, a linha teórica tomada conduzia a outra explicação para os problemas das sociedades europeias durante a belle époque: associava-os a determinações biológicas próprias a certos indivíduos, que representavam uma excrescência diante do desenvolvimento social e do futuro glorioso que a ciência parecia reservar à humanidade.

Essa linha teórica remonta ao século XIX ${ }^{12}$, sabendo-se que foi com a publicação de O homem delinquente (1876) pelo médico Cesare Lombroso (1835-1909) que uma teoria geral da criminalidade a partir de causas biológicas passou a ser considerada seriamente. O livro amalgamava teorias de áreas distintas para explicar um dos problemas sociais que tomava maior relevo no fim do século XIX: o crescimento da criminalidade nos grandes centros urbanos.

Lombroso empregava estatísticas criminais, medidas frenológicas e craniométricas para sustentar a tese de que boa parte dos criminosos era biologicamente condicionada a uma vida de crimes, constituindo um tipo à parte do resto da humanidade. Segundo Lombroso $(1983)^{13}$, por ação de causas de ordem moral, física e mental, esses indivíduos eram portadores de um atavismo que os tornava fortemente inclinados a atos criminosos desde o nascimento. Os estigmas do atavismo físico, enfatizados em sua obra, permitiam identificar o criminoso de modo mais objetivo: a presença de traços simiescos, assimetrias faciais, olhar oblíquo, alta resistência a dor física, uso de tatuagens, além de diversas características antropométricas cuja frequência Lombroso (1983, p.489-502) alegava ser maior entre os criminosos. Após a publicação de sua principal obra, revisada e ampliada em edições posteriores, e com o auxílio de seus discípulos Enrico Ferri (1856-1929) e Raffaele Garofalo (1851-1934), Lombroso passou a sustentar a tese de que a biologia dos criminosos natos determinava seu destino; eles constituíam tipos regressivos, bárbaros em meio à civilização (Carrara, 1998, p.99-100; Gould, 2003, p.122).

Há indícios de que essa teoria do 'criminoso nato' deveu seu sucesso muito mais a sua utilidade política para a associação entre criminalidade e pobreza e ao cientificismo peculiar à belle époque do que ao rigor metodológico de $\operatorname{Lombroso}^{14}$, mas o clima inicialmente receptivo a suas ideias logo deu margem a um embate direto com intelectuais franceses, sob a liderança de Gabriel Tarde, que se contrapunham ao determinismo biológico da antropologia criminal italiana. Nas edições subsequentes de O homem delinquente, Lombroso passou a considerar que fatores sociais poderiam condicionar a manifestação da criminalidade inata mais precoce ou tardiamente, entretanto, ele manteve a tese da determinação biológica em última instância (Morel, 1997, p.157).

Contudo, havia uma limitação incontornável na tese da criminalidade atávica, que decorria precisamente de seu absoluto essencialismo biológico, pois quando era aplicada nos tribunais, apenas permitia definir a 'temibilidade' do criminoso nato, ou seja, o mal que inevitavelmente causaria à sociedade. Dessa forma, não dava margem a qualquer ação profilática dirigida aos portadores de estigmas atávicos, universo por sinal expandido por Lombroso ao longo do tempo ${ }^{15}$, a não ser que se adotasse a prisão perpétua em massa, ou o genocídio dos 'criminosos natos', o que nem o próprio Lombroso julgava aceitável ${ }^{16}$ (Lombroso, 1983, p.XIX). Assim, apesar do prestígio inicial, a teoria do criminoso nato foi sendo ecplipsada no início do século XX pelo diagnóstico de 'psicopatia', em boa parte favorecido por um clima receptivo nos meios psiquiátricos e, sobretudo, criminológicos. 
O conceito de psicopatia emerge a partir das classificações oriundas de pelo menos três linhagens distintas da medicina mental: o alienismo francês até meados do século XIX; a psiquiatria britânica de meados século XIX; e a psiquiatria alemã do início do século XX. A despeito das divergências entre essas linhagens e seus membros, as classificações psicopatológicas e o debate a esse respeito produziram as condições de possibilidade para a emergência do diagnóstico de psicopata no século XX.

No âmbito do alienismo francês, tinha-se o ambíguo diagnóstico de 'mania sem delírio' de Philippe Pinel (2007) ${ }^{17}$, marcado por arroubos de agressividade desprovidos de alterações cognitivas. Mais tarde, Étienne Esquirol (1772-1840) isolou o diagnóstico de 'monomania' e seus subtipos: a intelectual; a afetiva; e a instintiva (Esquirol, 1838). Deve-se destacar que o alienismo francês descreveu em termos estritamente clínicos os diagnósticos mencionados, pois nem Pinel, nem Esquirol ou os demais alienistas faziam uso de juízos morais, mostrando muitas vezes simpatia pelos pacientes e destacando a ação da patologia com algo estranho a suas consciências. ${ }^{18}$ Nota-se que os diagnósticos posteriores são eivados por juízos morais negativos e parecem caracterizar, cada vez mais, um tipo humano distinto, não uma condição psíquica anormal ou patológica.

O alienista britânico James Prichard (1786-1848) foi um dos primeiros, fora da França, a redefinir a 'mania sem delírio' descrita por Pinel. A partir de observações clínicas próprias, ou enviadas por colegas ou ainda coletadas em jornais e outras fontes, ele identificou aquilo que batizou como moral insanity: "loucura que consiste em perversão mórbida dos sentimentos naturais, afetos, inclinações, temperamento, hábitos, disposições morais e impulsos naturais, desprovida de qualquer desordem observável ou defeito do intelecto ou faculdades de conhecimento e razão, particularmente sem nenhuma ilusão insana ou alucinação" (Prichard, 1835, p.58). A loucura moral seria uma perturbação isolada do senso moral e dos comportamentos sociais, sem lesão da inteligência nem das capacidades de raciocínio, o que parece sugerir um diagnóstico próximo aos do alienismo francês, contudo, duas diferenças fundamentais devem ser ressaltadas.

Em primeiro lugar, para Prichard, a loucura moral era um defeito socialmente repreensível (e não só uma patologia), o que destoa da atitude moralmente neutra das categorias de mania sem delírio e monomania propostas pelos franceses (Millon et al., 2003). Em segundo lugar, a categoria de Prichard abarcava gama muito mais ampla de casos clínicos e comportamentos socialmente criticáveis, como mendicância, prostituição etc., abrindo caminho para noções mais generalizantes, como degeneração, que se popularizariam ao longo do século XIX. Posteriormente, Henry Maudsley (1835-1918) procurou aperfeiçoar a descrição das 'loucuras morais' com o diagnóstico de 'imbecilidade moral' (Maudsley, 1895). Maudsley era, na Inglaterra, franco simpatizante da antropologia criminal de Lombroso (Harris, 1993), e sua influência predominou na psiquiatria inglesa até o início do século XX.

A psiquiatria alemã acabava de tomar o lugar de prestígio até então ocupado pelos franceses na medicina mental. Krafft-Ebing e Emil Kraepelin, os mais destacados psiquiatras alemães do período, partiram da teoria da degeneração de Morel (já em declínio) para afirmar a existência de um estado de predisposição a doenças mentais, um 'fundo comum' a partir do qual poderiam ser originadas diversas patologias mentais e do qual os comportamentos moralmente reprováveis ou perversos seriam indícios significativos. Krafft-Ebing restringiu- 
se mais à descrição das patologias sexuais decorrentes do que considerava disposições de comportamento perversas (Millon et al., 2003), enquanto Kraepelin, na última edição de seu Tratado de psiquiatria, publicada em 1915, forjava o diagnóstico de 'personalidade psicopática' (Pessotti, 1999), condição para a emergência do conceito de psicopatia.

Um trabalho publicado em 1941 e inscrito na tradição psiquiátrica norte-americana, A máscara de sanidade (1988), de Hervey Cleckley, pode ser considerado o marco fundamental na definição do conceito de psicopatia. ${ }^{19}$ A partir da observação clínica de pacientes hospitalizados, o autor definiu um quadro consistente de características que ainda podem ser encontradas na maior parte das escalas contemporâneas de mensuração da psicopatia (Arrigo, Shipley, 2001, p.334).

Segundo propôs Cleckley, as principais características do diagnóstico são: (1) carisma superficial e boa 'inteligência'; (2) ausência de delírios e outros sinais de pensamento irracional; (3) ausência de manifestações psiconeuróticas; (4) desonestidade; (5) mentira e insinceridade; (6) falta de remorso ou culpa; (7) comportamento antissocial sem motivo adequado; (8) juízo pobre, dificuldade em aprender com a experiência; (9) egocentrismo patológico e incapacidade de amar; (10) pobreza generalizada em reações afetivas maiores; (11) deficit específico de insight; (12) irresponsabilidade generalizada em relações interpessoais; (13) comportamento fantasioso e desagradável sob o efeito de álcool (às vezes sem); (14) rara ocorrência de suicídio; (15) vida sexual superficial, trivial e fracamente integrada; (16) fracasso em seguir um projeto de vida (Cleckley, 1988, p.338-339).

Excluído o fato de a maior parte dessas características ser mantida como critério para a aplicação do diagnóstico de psicopatia (e suas designações posteriores), o principal mérito de Cleckley (1988, p.383-387) subsiste na sua constatação de que muitos dos diagnosticáveis como psicopatas não estão nos hospitais psiquiátricos ou nas prisões. Esse autor estimava que apenas os psicopatas malsucedidos em manter uma 'máscara de sanidade' satisfatória acabavam em instituições de asilamento. A maioria deles não é percebida em sua natureza antissocial, por vezes ocupando papéis sociais de prestígio na ciência, nos negócios ou na política. Note-se que, ao longo das décadas do século XX, essa ênfase de Cleckley na máscara de sanidade como uma das principais características para o diagnóstico de psicopatia foi gradativamente abandonada, sabendo-se que as atuais escalas de mensuração de psicopatia empregam exclusivamente populações encarceradas para suas validações estatísticas. ${ }^{20}$

A hegemonia do estrutural-funcionalismo norte-americano na sociologia do pós-guerra acompanha sem contradição necessária o desenvolvimento de categorias como psicopatia e sociopatia e sua aplicação para diagnose de comportamentos socialmente desviantes. Mesmo a retomada da categoria de anomia por Merton (1970) e sua apropriação de alguns princípios da teoria psicanalítica freudiana não permitiram um questionamento cabal da condição patológica do indivíduo desviante. ${ }^{21}$

\section{A psicopatia ao longo das classificações internacionais}

A primeira nosologia padronizada foi criada pela American Medico-Psychological Association $^{22}$ em 1918, intitulada Statistical manual for the use of institutions for the insane, contava com apenas 22 diagnósticos, em sua maioria de psicoses e quadros crônicos 
encontrados nos hospitais psiquiátricos para os quais fora criada (Widiger, 2004). Em 1934, essa classificação passa por uma revisão, sendo incorporada à primeira edição da Standard classified nomenclature of disease da American Medical Association, embora ainda fosse constituída majoritariamente por diagnósticos comuns apenas em hospitais psiquiátricos. Durante a Segunda Guerra Mundial, tornou-se evidente a necessidade de mais uma revisão, pois $90 \%$ dos casos encontrados estavam fora de seu escopo. Isso levou as Forças Armadas e a Associação de Veteranos a criar classificações próprias nos anos seguintes (APA, 1952). Em 1948, a Organização Mundial da Saúde (OMS) publicou a sexta edição da International statistical classification of diseases, injuries, and causes of death (CID-6), a primeira a apresentar uma seção dedicada às doenças mentais. Como nos EUA coexistiam três nomenclaturas diferentes para as doenças mentais e nenhuma delas era coerente com a CID-6, a American Psychiatric Association (APA) constituiu um comitê com o objetivo de produzir uma classificação unificada (Viana, 2010).

Disso resultou a publicação do Diagnostic and statistical manual of mental disorders em 1952, posteriormente conhecido como DSM-I, que contava com 106 classificações de doenças mentais. O principal objetivo do DSM foi uniformizar os diagnósticos dos transtornos mentais nos EUA, permitindo o uso de designações equivalentes apesar das numerosas classificações psiquiátricas da época (Robertson, 2004). As categorias empregadas nessa classificação eram predominantemente psicodinâmicas, mais maleáveis à aplicação diagnóstica e menos específicas quanto à identificação de sintomas, sendo nítida a separação entre psicoses e neuroses (Dunker, Kyrillos Neto, 2011).

O quadro equivalente à psicopatia no DSM-I era designado como Distúrbio de Personalidade Sociopática (Sociopathic personality disturbance), que podia se manifestar de quatro maneiras diversas: reação antissocial, reação dissocial, desvio sexual e vício (a álcool e/ou drogas). O manual destaca que indivíduos alocados nessa categoria deveriam ser considerados doentes em relação à sua conformidade com o meio cultural vigente ou à sociedade como um todo. Observa-se que a definição adotada é explicitamente 'sociológica', pois não se restringe a uma caracterização dos traços individuais de personalidade, mas procura relacioná-los a seu meio social. A manifestação antissocial do distúrbio alude aos traços da descrição do diagnóstico de Cleckley, enfatizando o hedonismo, a frieza afetiva e a irresponsabilidade desses indivíduos como algo que lhes impede de estabelecer laços de lealdade com qualquer grupo ou pessoa. Já a manifestação dissocial decorre de o indivíduo desprezar os códigos sociais convencionais e não apresenta nenhum desvio para além dos implicados pela adesão a esse código anormal de conduta, frequentemente criminoso ou predatório (APA, 1952, p.38-39).

Em 1955, a OMS lançava a CID-7, alvo de duras críticas da comunidade psiquiátrica internacional, que com o reconhecimento da importância das doenças mentais pela comunidade científica da época consegue pressionar essa organização para a criação de um grupo de estudos para revisar a CID-7 (Viana, 2010). Como resultado disso, em 1968 foram publicados tanto a CID-8 quanto o DSM-II, com nomenclaturas mais homogêneas entre ambos, embora o DSM-II possuísse mais categorias (182) devido à ampliação da importância concedida às neuroses nessa edição (APA, 1968, p.39). Apesar da incorporação de termos da classificação de Kraepelin, as categorias empregadas nessa edição mantêm uma orientação 
psicodinâmica, e os sintomas descritos não são associados a distúrbios específicos (Dunker, Kyrillos Neto, 2011).

O abrangente 'distúrbio de personalidade sociopática' deu lugar à categoria 'personalidade antissocial'. Ela serviria para descrever indivíduos 'não socializados' e apresentava muitos dos traços de personalidade descritos por Cleckley: egoísmo, frieza afetiva, irresponsabilidade, impulsividade, incapacidade de sentir culpa e de aprender com a experiência e punição (APA, 1968, p.43). A classificação explicitava textualmente: “A mera história de repetidas ofensas sociais ou legais não é suficiente para justificar este diagnóstico"; sendo assim, o diagnóstico de personalidade psicopática não devia ser aplicado a criminosos. Eles haviam sido socializados, no entanto, conforme padrões de socialização segundo os quais os meios socialmente legítimos (por exemplo, trabalhar) não eram os únicos aceitos para alcançar as metas socialmente valorizadas (por exemplo, ter dinheiro). Nesse aspecto, o DSM-II é absolutamente coerente com as teorias sociológicas da época, tais como o estrutural-funcionalismo de Merton (1970) e os estudos sobre subculturas criminais de Cohen (1955). É desse alinhamento teórico com a sociologia que parece decorrer a reclassificação do distúrbio de personalidade sociopática com reações dissociais do DSM-I como 'comportamento dissocial' no DSM-II, classificado como um tipo de desajuste social sem manifestações psiquiátricas (APA, 1968, p.51).

O DSM-II foi alvo de duras críticas, pois, ao mesmo tempo em que buscava incorporar elementos sociológicos às suas classificações, conforme exposto, também se observava nessa classificação o ressurgimento da classe dos 'desvios sexuais', que considerava a homossexualidade uma perversão sexual, tornando a classificação da APA um alvo político importante para o movimento gay. Após intensas manifestações nas conferências de 1970 a 1973, a APA foi pressionada a retirar o termo homossexualidade do DSM-II em suas impressões posteriores, bem como deu início a um processo de revisão de toda a classificação devido à repercussão política dessa modificação, que atestava a fragilidade científica de sua classificação (Bayer, 1987, p.154).

Tanto o DSM-I quanto o DSM-II partiam de um modelo psicodinâmico, concebendo a relação entre normalidade e patologia como um contínuo, considerando as fronteiras entre a sanidade e a doença mental fluidas e admitindo que eventos estressantes podiam levar ao desenvolvimento de transtornos mentais, bem como o dinamismo psíquico podia levar ao desenvolvimento de um novo quadro diagnóstico a partir de um anterior (Viana, 2010). Diante disso, o DSM-III rompe abertamente com a linha psicodinâmica e adota um modelo nosológico categorial (Henriques, 2009); sua intenção é ser "ateórico com respeito a etiologia, descrevendo compreensivamente o que são as manifestações dos transtornos mentais (mental disorders)" (APA, 1980). A APA não explica de que modo seria possível esta tarefa paradoxal à qual o DSM-III se propõe: a criação de uma classificação que dispensa uma teoria prévia para a constituição de categorias, apenas a toma como uma premissa que embasa o assumido 'descritivismo' dessa edição associado à completa descaracterização da distinção entre neuroses e psicoses (Strand, 2011). O diagnóstico de 'neurose' é alvo de intensas controvérsias por ser considerado um termo etiológico e não descritivo pelos redatores do manual, o que deixa claro que a 'ateoricidade' intentada pelo DSM-III (endossada pelas classificações que lhe sucedem) em boa parte visa expurgar as categorias de orientação psicanalítica do manual (Mayes, Horwitz, 2005). Por fim, esse modelo procura definir os transtornos mentais sem 
referência às relações sociais ou com a sociedade, o que significa dizer que os reduz à sua manifestação individual (APA, 1980). ${ }^{23}$

Há uma mudança drástica quanto à caracterização da psicopatia tanto no DSM-III (APA, 1980) quanto em sua edição revisada DSM-III-R (APA, 1987). Conforme a orientação geral do manual, a ênfase nas relações sociais do indivíduo e nas 'causas ambientais' de sua antissocialidade foi preterida em prol de explicações estritamente 'comportamentais', consideradas mais precisas para a descrição do quadro clínico. O transtorno antissocial de personalidade (Tasp) descreve um indivíduo com um padrão crônico de infrações legais e comportamentos antissociais iniciados desde a infância. Efetivamente, a aplicação do diagnóstico de Tasp restringe-se à prática de atos criminosos, ao mesmo tempo em que estende a aplicação desse diagnóstico à maior parte dos autores de crimes encarcerados. Isso permite a autores como McCallum (2001) sustentar a crítica de que, a partir do DSM-III evidencia-se a tendência da APA à progressiva patologização de condutas criminais, simultaneamente ao 'endurecimento' da política criminal norte-americana a partir da década de 1980.

A partir das críticas ao diagnóstico de Tasp conforme a definição do DSM-III, o texto do DSM-IV esclarece que essa classificação também pode ser referida por "psicopatia, sociopatia ou transtorno dissocial de personalidade" (APA, 1994, p.645). Embora a intenção dos revisores fosse diminuir as ambiguidades existentes entre essas diferentes categorias, o resultado foi uma oposição ainda mais vigorosa dos críticos à categoria de Tasp, devido às confusões geradas por essa equivalência 'convencionada' entre diagnósticos, estabelecida pela nova redação do texto do Tasp no DSM-IV. Um desses críticos é o psiquiatra Robert Hare, criador da Psychopathy Checklist Revised (PCL-R), uma das escalas de mensuração de psicopatia mais amplamente utilizadas na atualidade. Segundo Hare (2003), a classificação de Tasp é insatisfatória pelo fato de demandar uma subdivisão implícita entre os sujeitos diagnosticados na população em geral e aqueles submetidos à justiça criminal. Ao defender o diagnóstico que sua escala visa mensurar, esse autor afirma: “O fato é que 'psicopatia' é um dos construtos clínicos com melhor validação no âmbito da psicopatologia e, presumivelmente, o construto clínico mais importante para o sistema de justiça criminal" (p.189).

Eis aqui o último capítulo da história iniciada pela cisão radical entre sociologia e psicologia ante os comportamentos social ou individualmente patológicos, desviantes ou propriamente criminais: a criação de escalas individuais de mensuração de psicopatia ou 'risco (de reincidência) criminal', como a PCL-R. Tais escalas atualmente tornaram-se o instrumento privilegiado para a tomada de decisões quanto à administração da justiça criminal nos EUA, Canadá e boa parte da Europa e mesmo ao risco potencial representado por indivíduos com comportamento desviante (Arrigo, Shipley, 2001). Uma análise mais atenta permite identificar um efeito preocupante da definição da categoria de Tasp. Uma vez que os atos criminosos passam a ser considerados uma característica comportamental, não mais uma forma de confronto com a sociedade, conforme DSM-III e seus sucessores, o que acaba ocorrendo é uma 'patologização' da criminalidade, uma vez que as escalas de mensuração de psicopatia como a PCL-R são aplicadas massivamente em indivíduos encarcerados e acabam sendo indicadas pelos psiquiatras como um construto útil para a administração do sistema de justiça criminal (Morana, Câmara, Arboleda-Florez, 2006). 


\section{Considerações finais}

A partir da reconstituição histórico-conceitual realizada até aqui, procurou-se destacar que há poucos pontos de contato entre a teoria sociológica sobre a criminalidade e o desvio social e a discussão psiquiátrica da psicopatia, sendo o diagnóstico mais diretamente relacionado a condutas antissociais ou criminais. Até o fim do século XIX, o debate entre esses dois domínios teóricos era relativamente intenso, mesmo que de modo conflitivo, como se observou entre os sociólogos franceses liderados por Tarde e a antropologia criminal italiana. Contudo, a cisão epistemológica entre a sociologia científica de Durkheim e a psicologia parecem ter levado a um desinteresse progressivo por parte da sociologia e das ciências sociais em geral com relação às discussões psicológicas e psiquiátricas. Por outra parte, após a publicação do DSM-III e seus sucessores, a intenção explícita do manual de desconsiderar relações sociais e com a sociedade de um modo geral leva as classificações psiquiátricas a um extremo reducionismo, especialmente no que se refere à psicopatia, pois o crime deixa de ser percebido como um ato socialmente condicionado para se tornar um indicador objetivo, um conjunto de sintomas do transtorno antissocial de personalidade, o que significa um franco reducionismo individual de comportamentos considerados criminosos.

Ainda no que se refere à psicopatia, no âmbito contemporâneo, pode-se identificar pelo menos três posições quanto ao debate dessa categoria: a franca defesa do construto e do rigor científico alcançado pela mensuração da psicopatia por meio de escalas, como defende Hare (2003); a crítica à mensuração do construto e sua utilidade clínica, como a realizada por Vassileva (2005) e Rutter (2005); e a crítica radical do construto, visando apresentá-lo como cientificamente inconsistente e desprovido de sustentação empírica confiável, como são exemplo os trabalhos de Jalava (2006) e Arrigo e Shipley (2001). A despeito das posições defendidas pelos autores que se dedicam a essa temática, seus trabalhos têm em comum o fato de construir uma história do conceito de psicopatia de modo retrospectivo. Eles descrevem a sucessão das categorias que precederam o conceito de psicopatia, privilegiando o seu caráter contínuo. Por um lado, para sustentar a validade do conceito enquanto um construto clínico que se reporta a um 'objeto natural', argumentando que ele corresponderia a um estado mental constante em diferentes épocas (Hare, 2003). Por outro lado, para criticar essa aparente continuidade de ordem empírica por meio da denúncia de sobrevivências teóricas pré-científicas nas classificações atuais (Jalava, 2006). Sendo assim, constata-se que até mesmo as críticas ao diagnóstico de psicopatia partem da psicologia ou da própria psiquiatria; à exceção do trabalho de McCallum (2001), não se encontram pesquisas sociológicas ou no âmbito das ciências sociais que abordem essa questão.

Seguramente, assim existe uma sucessão entre categorias, e elas possuem algum parentesco; contudo, também há momentos de quebra, de "ruptura epistemológica", como diria Bachelard (1996), nos quais a descontinuidade entre a sucessão de duas categorias é mais importante do que as suas semelhanças. Todavia, não se deve exagerar na ênfase e procurar fazer uma história do conceito apenas através de 'descontinuidades'. Seguindo as proposições de Canguilhem (1979), compartilhadas por Foucault (2012), procurou-se apresentar uma breve síntese histórica do conceito de psicopatia neste artigo, considerando movimentos de continuidade e descontinuidade. Esse procedimento visa compreender como indícios 
e sintomas atualmente utilizados nas classificações estatisticamente validadas, ou seja, no domínio da 'ciência sancionada', advêm de teorias que há muito caíram em descrédito e, portanto, são atualmente consideradas 'ciência superada' ${ }^{24}$

Apesar do rigor psicométrico e da validação empírica obtida por Hare na aplicação da PCL-R, que representa a ciência sancionada segundo os cânones psicométricos, críticos têm ressaltado algumas características perturbadoras desse instrumento, que se reportam diretamente a elementos das aludidas ciências superadas, especialmente os determinismos antropométricos e juízos morais do século XIX. A maior parte dos indicadores para psicopatia presentes na PCL-R foram operacionalizados a partir das categorias formuladas por Cleckley (1988). Desse modo, por mais que a PCL-R esteja de acordo com os preceitos científicos para a validação estatística de uma escala, restam algumas objeções a que Hare não respondeu satisfatoriamente em seus trabalhos publicados até o momento.

Em primeiro lugar, o viés implicado pela validação de sua escala ser restrita à amostragem em populações carcerárias, não sendo, portanto, generalizável para a toda a população (ou seja, a crítica que ele mesmo dirige ao diagnóstico de Tasp é igualmente aplicável a sua própria escala), restringindo consideravelmente a aplicabilidade clínica do construto 'psicopatia'. Além disso, críticos como Walters (2004) indicam que o uso indiscriminado da PCL-R costuma levar a numerosos diagnósticos de 'falsos positivos', ou seja, indivíduos que são classificados como psicopatas indevidamente (por falha na aplicação do instrumento por parte do entrevistador ou em decorrência de uma contratransferência negativa), e podem acabar envolvendo-se em condutas ilegais mais por carregar o estigma de psicopata (e pela restrição a ocupações profissionais não ilegais disso decorrentes), do que por disposições prévias de personalidade.

Enfim, por mais que a PCL-R seja proposta como um instrumento científico para a mensuração da psicopatia, o próprio diagnóstico implicado pelos indicadores da escala ainda está carregado por uma forte carga de condenação moral (por exemplo, mentira patológica, estilo de vida parasitário, comportamento sexual promíscuo, falta de projetos de longo prazo realísticos, irresponsabilidade, múltiplas relações maritais de curta duração etc.). Como sugere John Gunn (2003), o principal problema moral implicado por essa escala é a redução de uma série de comportamentos distintos a uma única categoria sintética que não auxilia a compreender ou investigar as fontes desses diversos comportamentos moralmente recrimináveis e correlacionados, mas permite etiquetá-los satisfatoriamente. Nesse ponto, as ressurgências das teorias há muito 'superadas' da loucura moral e da degeneração fazem-se ouvir em meio a um insuspeito instrumento psicométrico, exemplo de rigor segundo os critérios do que hoje seja cientificamente 'sancionado'.

Embora possam parecer erros prosaicos ao olhar sociológico, as limitações do emprego de escalas de mensuração de psicopatia como meio de administração da justiça criminal, a rápida multiplicação desses instrumentos e a expansão de seu uso em diversos países parecem ser um indicador importante de que a sociologia está omitindo-se de um debate importante. Possivelmente devido ao temor do voluntarismo implícito em algumas das asserções de Durkheim sobre o papel do sociólogo ou mesmo o asco do espectro fantasmático implicado pelas categorias de anomia ou, por que não dizer, patologia social, as pesquisas sociológicas acabaram por abrir espaço à proliferação de discursos que reduzem o desvio social e a 
criminalidade (ou ao menos os casos mais graves desses dois fenômenos) a explicações de caráter individualmente patologizante, como o diagnóstico de psicopata, ou ainda ao emprego de rótulos a partir de escalas 'científicas', como é o caso da aplicação do Tasp em condenados.

Um dos principais intentos deste artigo é propor um debate mais direto entre sociologia e psiquiatria a partir da reflexão histórico-conceitual desses dois domínios teóricos no que se refere às teorias do controle social e da criminalidade. A incontornável discussão da normalidade e da patologia, em termos individuais e coletivos, inevitavelmente implica uma discussão entre esses domínios, que hoje se encontram praticamente isolados. O preço do silêncio sobre essa questão parece ser a ressurgência do discurso da patologização individual do desvio e da criminalidade sustentado por uma suposta autoridade quantitativa representada por escalas como a PCL-R, que, no entanto, resguarda heranças perigosas de discursos que ingenuamente se julga estarem para sempre superados.

\section{NOTAS}

${ }^{1}$ Em alguns casos, o uso de modelos epidemiológicos para a análise de fenômenos sociais torna esse emprego da 'sociedade como um organismo' mais explícito (Silva, 2004), enquanto pesquisadores como Minayo $(1994 ; 2006)$ procuram fazer um emprego reflexivo desse tipo de modelo.

${ }^{2}$ Um exemplo disso é oferecido no artigo “A evolução da noção de 'indivíduo perigoso' na psiquiatria legal do século XIX", no qual Foucault descreve como, a partir dos 'crimes sem razão', a medicina entra nos tribunais ao fim do século XVIII e configura as condições de possibilidade para que, cerca de um século após, uma tendência penal que contradiz frontalmente os preceitos (humanistas e igualitários) dos quais os primeiros códigos penais partiam seja formulada: a teoria do criminoso nato da escola de antropologia criminal italiana. Segundo Foucault (2004, p.24), essa tendência, embora de modo mais sutil, exerce os seus efeitos até o presente, pois o que temos hoje é: "Uma justiça que tende a se exercer sobre aquilo que se é: aqui está o que é exorbitante em relação a este direito penal que os reformadores do século XVIII haviam imaginado, e que deveria punir, de maneira absolutamente igualitária, as infrações explícita e previamente definidas pela lei".

${ }^{3}$ O presente artigo adota a classificação proposta por Raymond Aron (1999, p.65-67) para a obra de Comte: (1) uma etapa na qual o autor apresenta suas ideias quanto à necessária reforma social e intelectual das sociedades industriais, tendo como principal obra os Opúsculos de filosofia social de 1822; (2) a segunda etapa é aquela na qual ele se ocupa mais diretamente da sociologia e apresenta seu sistema de pensamento positivista ao longo do extenso Curso de filosofia positiva, escrito e publicado entre 1830 e 1842; (3) por fim, o período mais controverso de sua obra, no qual Comte desenvolve a ideia da 'religião da humanidade' e publica o Sistema de política positiva ou Tratado de sociologia instituindo a religião da humanidade, entre 1851 e 1854.

${ }^{4}$ Segundo Canguilhem, Broussais é muito mais normativo do que gostaria de admitir: "[Em Broussais] mais ainda do que na obra de Comte, pode-se notar a imprecisão das noções de 'excesso' e 'falta', seu caráter implicitamente qualitativo e normativo, apenas dissimulado sob sua pretensão métrica. É em relação a uma medida considerada válida e desejável - e, portanto, em relação a uma norma - que há excesso ou falta. Definir o anormal por meio do que é de mais ou de menos é reconhecer o caráter normativo do estado dito normal. Esse estado normal ou fisiológico deixa de ser apenas uma disposição detectável e explicitável como um fato para ser a manifestação do apego a algum valor" (Canguilhem, 2006, p.26).

${ }^{5}$ A menção ao conceito de ideologia nesse contexto tem o sentido atribuído ao conceito por Canguilhem (1977), não o usualmente atribuído a ele pela tradição de pensamento marxista.

${ }^{6}$ Robert Nye (1996) descreve o contexto social francês que antecedeu os escritos de Durkheim, no qual intelectuais e dirigentes políticos estavam preocupados com o 'declínio da nação francesa', manifesto pela decadência cultural (a boemia dos cafés), declínio das taxas de natalidade (era o país que menos 'crescia' no século XIX) e crescentes índices de suicídio e criminalidade (no caso da criminalidade as taxas absolutas aumentavam, sobretudo, pela própria ação policial, mas os intelectuais europeus do período vitoriano acreditavam que o aumento dos 'crimes de sangue' era um dos preços do progresso).

${ }^{7}$ A passagem mais clara nesse sentido é a citação seguinte, na qual é evidente o emprego da analogia organicista: "Mesmo que o ato seja certamente nocivo à sociedade, é preciso que o grau de nocividade que apresenta esteja regularmente em relação com a intensidade da repressão que o atinge. No direito penal 
dos povos mais civilizados, o assassínio é universalmente visto como o maior dos crimes. Entretanto, uma crise econômica, uma quebra na bolsa, mesmo uma falência podem desorganizar muito mais gravemente o corpo social do que um homicídio isolado. Que é um homem a menos na sociedade? Que é uma célula a menos no organismo?" (Durkheim, 1973, p.338).

${ }^{8} \mathrm{O}$ combate às chamadas patologias sociais motivou publicações como a de Carlier, intitulada Études de pathologie sociale: les deux prostitutions (1887), na qual defendia a necessidade da criação de uma polícia de costumes para a vigilância e regulamentação da prostituição feminina tanto quanto para o combate à verdadeira patologia social que, para ele, constituía a 'prostituição antinatural' representada pela 'pederastia'. Já René Worms, principal expoente do organicismo francês, em Organisme et societé (1896) corrobora e amplia o organicismo sociológico de Spencer. Em uma linha igualmente organicista, Paul Lilienfeld publica Pathologie sociale (1896), prefaciado por Worms e explicitamente filiado ao organicismo sociológico de Spencer.

${ }^{9}$ Nessa e nas demais citações de textos em língua estrangeira, a tradução é livre.

${ }^{10}$ Deve-se observar que Quetelet e Durkheim concebem de modos bastante diversos a distinção entre normalidade e patologia. Segundo Halbwachs (1913), há uma teleologia intrínseca ao pensamento de Quetelet, ele concebe que o normal é ideal e apenas nesse contexto ele concebe que o crime, embora anormal em si, é regular estatisticamente. Já Durkheim não vê uma diferença ontológica entre o normal e o patológico, a existência de crimes e suicídios, por exemplo, pode ser acompanhada por distribuições estatísticas, mas suas variações ao longo de determinados períodos podem decorrer de fatores anômicos, de estados sociais patológicos como crises econômicas, revoluções políticas violentas etc. Em suma, embora Quetelet tenha precedido Durkheim na identificação de que há uma frequência constante na criminalidade, de acordo com a interpretação de Halbwachs, pode-se afirmar que ele não consegue levar a cabo as consequências de sua constatação estatística e considerar o crime uma ocorrência normal, mas sim uma anormalidade recorrente (Halbwachs, 1913, p.155-161).

${ }^{11} \mathrm{O}$ repúdio à posição de Durkheim sobre a questão chegou a despertar manifestações no Brasil, onde o jurista Paulo Egydio dedicou um livro inteiro, intitulado Sociologia criminal (1900), à refutação da tese de Durkheim, em defesa da escola de antropologia criminal e na anormalidade constitutiva do indivíduo criminoso.

${ }^{12}$ Vários autores franceses empregaram o conceito de 'degeneração' para explicar o declínio moral progressivo, sempre acompanhado do aumento da criminalidade, que se observava na França do século XIX. Pick (1996) ocupa-se especificamente dessa discussão, que também é mencionada de modo mais incidental em Darmon (1991), Harris (1993) e Rafter (1997).

${ }^{13}$ A obra consultada foi uma tradução feita a partir da edição francesa de 1884.

${ }^{14}$ Segundo Gould (2003, p.136), Lombroso era criticado pelo enviesamento e apriorismo de suas publicações por seus contemporâneos. Além disso, o autor abusava do artifício retórico do argumento de autoridade em seus livros, que geralmente traziam suas páginas iniciais cobertas por nomes de inúmeras autoridades científicas dos mais diversos países que, segundo Lombroso, endossavam a sua tese do 'criminoso nato'.

${ }^{15}$ Nas últimas edições de O homem criminoso a criminalidade atávica havia sido ampliada a ponto de compreender todos os casos de 'loucura parcial', os quadros 'degenerativos' descritos por Morel e seus discípulos, a epilepsia e o restante dos casos nos quais os estigmas físicos do atavismo eram mais evidentes do que os mentais. Entretanto, deve-se destacar que, apesar da importância que Lombroso atribuía à criminalidade inata, ele jamais concebeu que a totalidade dos crimes decorresse de atos cometidos por portadores de estigmas atávicos. Sua estimativa era de que cerca de $40 \%$ dos crimes obedeciam a um impulso hereditário (Lombroso, 1983, p.502), sendo os demais cometidos em decorrência da paixão, da fúria ou do desespero (Gould, 2003, p.130).

${ }^{16}$ Segundo a indicação de Darmon (1991, p.198-200), a proposta eugenista mais extrema foi publicada em 1918 por Binet-Sanglé no seu livro O haras humano (1918), que prescrevia o extermínio de criminosos natos e degenerados e o incentivo à procriação das elites humanas.

${ }^{17} \mathrm{O}$ tratado de Philippe Pinel (1765-1826), publicado originalmente em 1809, foi basilar para o alienismo do século XIX por reduzir a pouquíssimas categorias diagnósticas as complicadas e numerosas classificações da alienação mental então existentes.

${ }^{18}$ A descrição de Pinel quanto a um paciente que padecia de quadro crônico de mania sem delírio é ilustrativa quanto à caracterização empática desses quadros, enfatizando mais o sofrimento do paciente do que o perigo por ele representado: "Posso tornar sensível, por um exemplo, o mais alto grau de desenvolvimento desta espécie de alienação. Um homem, entregue outrora à arte da mecânica e recluso atualmente em Bicêtre, experimenta, em intervalos regulares, acessos de fúria marcados pelos seguintes sintomas: primeiro, sentimento de abrasadora queimação nos intestinos, com sede intensa e forte constipação; este calor propaga-se 
aos poucos até o peito, o pescoço, o rosto, com um colorido mais vivo, produzindo batimentos muito fortes e frequentes nas artérias dessas partes, como se estas fossem romper-se; enfim, a afecção nervosa ganha o cérebro, e então 'o alienado é dominado por uma tendência sanguinária irresistível'; e, se conseguir se apossar de um instrumento cortante, é levado a sacrificar com uma espécie de fúria a primeira pessoa que lhe aparece sob as vistas. Goza, entretanto, do livre exercício de sua razão quanto a outros aspectos, mesmo durante seus acessos; responde diretamente às questões que lhe são feitas, não deixando escapar nenhuma incoerência nas ideias, nenhum sinal de delírio. Sente 'mesmo profundamente todo o horror de sua situação; sendo penetrado pelo remorso, como se tivesse de censurar-se esta tendência furiosa'. Antes de sua reclusão na Bicêtre, 'tal acesso de furor tomou-o um dia em sua casa; conseguiu advertir sua esposa, que aliás, ele amava, não tendo senão o tempo de gritar-lhe para que fugisse rapidamente, para se livrar de uma morte violenta' (Pinel, 2007, p.172, grifos meus). Em síntese, os sintomas físicos envolvendo o 'ataque de fúria', o remorso que o sucede e o incidente envolvendo a esposa parecem aproximar o quadro de mania sem delírio descrito por Pinel mais do furor na concepção grega (como o furor pelo qual Hércules foi tomado, matando sua família) do que com os diagnósticos que o sucedem.

${ }^{19}$ Cabe mencionar o diagnóstico de 'personalidade psicopática' de Kurt Schneider. Esse autor segue a tradição alemã iniciada com Kraepelin, mas se diferencia de muitos de seus contemporâneos por adotar a premissa de que a personalidade psicopática é 'anormal' em um sentido não necessariamente pejorativo. Segundo ele, "Partindo desta normalidade média, é exatamente tão anormal o santo ou o grande poeta como o criminoso desalmado, os três caem fora do termo médio das personalidades. É evidente que todas as personalidades, de alguma maneira singulares ou estranhas, especialmente as que se destacam por algum traço de seu modo de ser, têm que ser incluídas sob este conceito" (Schneider, 1968, p.31). Apesar da originalidade do pensamento de Schneider, dado que a psiquiatria norte-americana passa ao largo de sua contribuição, optou-se por partir da definição de Cleckley, que serve como fundamento para as modernas escalas de mensuração da psicopatia que serão discutidas ao final do artigo.

${ }^{20}$ Praticamente todos os artigos contemporâneos que indicam a aplicação de uma escala de mensuração de psicopatia são aplicados em instituições penitenciárias, tais como Vien e Beech (2006), Murphy e Vess (2003) e, no Brasil, Morana, Câmara e Arboleda-Florez, 2006.

${ }^{21}$ Gabriel Anitua (2008, p.474) procura sustentar interpretação diversa sobre esses dois autores: "Seguindo com grande rigor a Durkheim, Merton opunha-se, portanto, a qualquer concepção patológica do comportamento desviado. ... Para Merton, a estrutura social não se opõe, subjuga nem domina o indivíduo, mas sim constitui com ele um todo indissociável. Pelo mesmo motivo, a sociedade não só gera rebeldia e a sanciona como patológica, mas produz também, antes de tudo, consenso. Basicamente, a sociedade não pode ser pensada em termos individuais". No entanto, parece autoevidente que, se a sociedade não pode ser pensada em termos individuais, o crime, de fato, não pode ser pensado com um fenômeno socialmente patológico, mas nada haveria de contraditório em constituir-se a psicopatia como uma causa de comportamento desviante determinada individualmente, por uma condição psíquica patológica.

${ }^{22}$ Essa instituição passou a se chamar American Psychiatric Association em 1921.

${ }^{23} \mathrm{Na}$ definição da expressão transtorno mental o manual explicita: “Trata-se de uma disfunção comportamental, psicológica ou biológica, e esse distúrbio não se refere apenas à relação entre indivíduo e sociedade (Quando o distúrbio está limitado ao conflito entre indivíduo e sociedade, ele pode representar desvio social, que pode ou não ser elogiável, mas que em si não constitui um transtorno mental)" (APA, 1980, p.6). Conquanto a intenção do texto pareça ser explicitar que o manual quer evitar cometer erros como o da classificação da 'homossexualidade' ou a patologização de comportamentos desviantes como a delinquência juvenil (classificada entre os transtornos mentais da infância e adolescência no DSM-II), o resultado prático dessa definição é o reducionismo individualista dos diagnósticos, com consequências diretas sobre a discussão da psicopatia.

${ }^{24}$ Canguilhem (1979) utiliza as expressões 'ciência superada' [connaissances périmées] (o pré-científico ou o domínio da formação discursiva que constitui um 'saber', segundo Foucault) e 'ciência sancionada' [connaissances sanctionées] (o domínio de uma formação discursiva considerada científica, ou 'no verdadeiro', segundo Foucault) a partir da distinção proposta por Bachelard (1996) entre história superada e história sancionada. 


\section{REFERÊNCIAS}

APA.

American Psychiatric Association. Diagnostic and statistical manual. Mental disorders. 4.ed. revised. Washington: APA. 1994.

APA.

American Psychiatric Association. Diagnostic and statistical manual. Mental disorders. 3.ed. revised. Washington: APA. 1987.

APA.

American Psychiatric Association. Diagnostic and statistical manual. Mental disorders. 3.ed. Washington: APA. 1980.

APA.

American Psychiatric Association. Diagnostic and statistical Manual. Mental disorders. 2.ed. Washington: APA. 1968.

APA.

American Psychiatric Association. Diagnostic and statistical manual. Mental disorders. Washington: APA. 1952.

ANITUA, Gabriel Ignacio.

História dos pensamentos criminológicos.

Rio de Janeiro: Revan. 2008.

ARON, Raymond.

As etapas do pensamento sociológico. São Paulo:

Martins Fontes. 1999.

ARRIGO, Bruce; SHIPLEY, Stacey.

The Confusion over psychopathy (I): historical considerations. International Journal of Offender Therapy and Comparative Criminology, Thousand Oaks, v.45, n.3, p.325-344. 2001.

BACHELARD, Gaston.

A formação do espírito científico. Rio de Janeiro: Contraponto. 1996.

BARBERIS, Daniela S.

In search of an object: organicist sociology and the reality of society in fin-de-siècle France, History of the Human Sciences, Thousand Oaks, v.16, n.3, p.51-72. 2003.

BAYER, Ronald.

Homosexuality and American psychiatry: the politics of diagnosis. Princeton: Princeton University Press. 1987.

BECKER, Howard.

Segredos e truques da pesquisa. Rio de Janeiro: Zahar. 2007.

BENOIT, Lelita Oliveira.

Sociologia comteana: gênese e devir. São Paulo: Discurso Editorial. 1999.

BINET-SANGLÉ, Charles.

Le haras humain. Paris: Albin Michel. 1918.
BOUDON, Raymond, BOURRICAUD, François. Dicionário crítico de sociologia. São Paulo: Ática. 2004.

CANGUILHEM, Georges.

O normal e o patológico. Rio de Janeiro: Forense Universitária. 2006.

CANGUILHEM, Georges.

Études d'histoire et de philosophie des sciences. Paris: Vrin. 1979.

CANGUILHEM, Georges.

Ideologia e racionalidade nas ciências da vida.

Lisboa: Edições 70. 1977.

CARLIER, François.

Les deux prostitutions. Paris: Editeur E. Dentu. 1887.

CARRARA, Sérgio.

Crime e loucura: o aparecimento do manicômio judiciário na passagem do século. Rio de Janeiro: Eduerj; Edusp, 1998.

CARRION, Rejane.

A ideologia médico-social no sistema de Auguste Comte. Cadernos do IFCH-UFRGS, Porto Alegre, n.1. 1977.

CLECKLEY, Hervey.

The mask of sanity: an attempt to clarify some issues about the so called psychopathic personality. Augusta: Emily Cleckley (private printing for non-profit educational use). 1988.

COELHO, Ruy.

Indivíduo e sociedade na teoria de Auguste Comte.

São Paulo: Perspectiva. 2005.

COHEN, Albert K.

Delinquent boys: the culture of the gang. Glencoe: The Free Press. 1955.

COMTE, Auguste.

Opúsculos de filosofia social. São Paulo: Edusp; Globo. 1972.

COMTE, Auguste.

Cours de philosophie positive. Tome 1. Paris: Rouen Frères. 1830.

CONSOLIM, Marcia Cristina.

Gabriel Tarde e as ciências sociais francesas: afinidades eletivas. Mana, Rio de Janeiro, v.2, n.14, p.269-198. 2008.

DARMON, Pierre.

Médicos e assassinos na Belle Époque. Rio de Janeiro: Paz e Terra. 1991.

DELAPORTE, François.

A história das ciências segundo Georges

Canguilhem. In: Portocarreiro, Vera (Org.). 
Filosofia, história e sociologia das ciências: abordagens contemporâneas. Rio de Janeiro: Fiocruz. 1994.

DUNKER, Christian Ingo Lenz; KYRILLOS NETO, Fuad.

A crítica psicanalitica do DSM-IV: breve história do casamento psicopatológico entre psicanálise e psiquiatria. Revista Latinoamericana de Psicopatologia Fundamental, São Paulo, v.14, p.611-626. 2011.

DURKHEIM, Émile.

De la division du travail social. Paris: Presses

Universitaires de France. 2004.

DURKHEIM, Émile.

Le suicide. Paris: Quatrige; Presses Universitaires de France. 1993.

DURKHEIM, Émile.

Les regles de la méthode sociologique. 21.ed. Paris: Quatrige; Presses Universitaires de France. 1.ed. 1895. 1983.

DURKHEIM, Émile.

Da divisão do trabalho social. São Paulo: Abril

Cultural. 1973.

EGYDIO, Paulo.

Estudos de sociologia criminal: do conceito geral do crime segundo o método contemporâneo (a propósito da teoria de E. Durkheim). São Paulo: Tipografia e Edição da Casa Eclética. 1900.

ESQUIROL, Étienne.

Des maladies mentales: considérées sous les rapports médical, hygiénique et médico-légal. Paris: Baillière. 3v. 1838.

FOUCAULT, Michel.

Arqueologia do saber. Rio de Janeiro: Forense Universitária. 2012.

FOUCAULT, Michel.

A evolução da noção de "indivíduo perigoso" na psiquiatria legal do século XIX. In: Foucault, Michel. Ética, sexualidade, política: ditos e escritos, v.5. Rio de Janeiro: Forense Universitária. 2004.

GOULD, Stephen Jay.

A falsa medida do homem. São Paulo: Martins Fontes. 2003.

GUNN, John.

Psycopathy: an elusive concept with moral overtones. In: Millon, Theodore et al.

Psychopathy: antisocial, criminal and violent behavior. New York: The Guildford Press. p.3239. 2003.

HALBWACHS, Maurice.

La théorie de l'homme moyen: essai sur Quételet et la statistique morale. Paris: Félix Alcan. 1913.
HARE, Robert.

Psycopaths and their nature: implications for the mental health and criminal justice systems. In: Millon, Theodore et al. Psychopathy: antisocial, criminal and violent behavior. New York: The Guildford Press. 2003.

HARRIS, Ruth.

Assassinato e loucura: medicina, leis e sociedade no fin de siècle. Rio de Janeiro: Rocco. 1993.

HENRIQUES, Rogério Paes.

De H. Cleckley ao DSM-IV-TR: a evolução do conceito de psicopatia rumo à medicalização da delinquência. Revista Latinoamericana de Psicopatologia Fundamental, São Paulo, v.12, n.2, p.285-302. 2009.

HUXLEY, Julien.

Sobre a história da ciência. In: Huxley, Julien. Os fenômenos da vida. São Paulo: Companhia Editora Nacional. 1941.

JALAVA, Jarkko.

The modern degenerata: nineteenth-century degeneration, theory and modern psychopathy research. Theory Psychology, Thousand Oaks, v.16, n.3, p.416-432. 2006.

LILIENFELD, Paul de.

La pathologie sociale. Paris: V.Giard et E.Brière. 1896.

LOMBROSO, Cesare.

O homem criminoso. Rio de Janeiro: Editora Rio. 1983.

LUKES, Steven.

Bases para a interpretação de Durkheim. In:

Cohn, Gabriel (Org.). Sociologia: para ler os clássicos. Rio de Janeiro: Azougue. p.15-54. 2005.

MALINOWSKI, Bronislaw.

Crime e costume na sociedade selvagem. Brasília:

EdUnB. 2008.

MAUDSLEY, Henry.

The pathology of mind: a study of its distempers, deformities and disorders. London: MacMillan. 1895.

MAYES, Rick, HORWITZ, Allan V.

DSM-III the revolution in the classification of mental illness. Journal of the History of the Behavioral Sciences, Hoboken, v.41, n.3, p.249267. 2005.

MAYR, Ernst.

Some thougths on the history of the evolutionary synthesis. In: Mayr, Ernst; Provine, Willian B. (Ed.). The evolutionary syntesis: perspectives on the unification of biology. Cambridge: Harvard University Press. 1998.

MCCALLUM, David.

Personality and dangerousness: genealogy of 
antisocial personality disorder. Cambridge: Cambridge University Press. 2001.

MCDONALD, Lynn.

Theory and evidence of rising crime in the nineteenth century. The British Journal of Sociology, London, v.33, n.3, p.404-420. 1982.

MERTON, Robert King.

Sociologia: teoria e estrutura. São Paulo: Mestre Jou. 1970.

MILLON, Theodore et al.

Historical conceptions of psychopathy in the United States and Europe. In: Millon, Theodore et al. Psychopathy: antisocial, criminal and violent behavior. New York: The Guildford Press. p.3-31. 2003.

MINAYO, Maria Cecília de S.

Violência e saúde. Rio de Janeiro: Editora Fiocruz. 2006.

MINAYO, Maria Cecília de S.

A violência sob a perspectiva da saúde pública. Cadernos de Saúde Pública, Rio de Janeiro, v.10, supl. 1, p.7-18. 1994.

MORANA, Hilda Clotilde; CÂMARA, Fernando Portela; ARBOLEDA-FLOREZ, Julio.

Cluster analysis of a forensic population with antisocial personality disorder regarding PCL-R scores: differentiation of two patterns of criminal profiles. Forensic Science International, Amsterdam, v.164, n.2-3, p.98-101. 2006.

MOREL, Pierre.

Dicionário biográfico psi. Rio de Janeiro: Jorge Zahar. 1997.

MUCCHIELLI, Laurent.

O nascimento da sociologia na universidade francesa (1880-1914), Revista Brasileira de História, São Paulo, v.21, n.41, p.35-54. 2001.

MURPHY, Carolyn; VESS, James. Subtypes of psychopathy: proposed differences between narcissistic, borderline, sadistic and antisocial psychopaths. Psychiatric Quarterly, Berlin, v.74, n.1, p.11-29. 2003.

NYE, Robert.

Heredity, pathology, and psychoneurosis in Durkheim's early work. In: Hamilton, Peter. Émile Durkheim: critical assessments. London: Routledge. 1.ed., 1982. 1996.

PESSOTTI, Isaias.

Os nomes da loucura. São Paulo: Editora 34. 1999.

PICK, Daniel.

Faces of degeneration: a European disorder, c.18481918. Cambridge: Cambridge University Press. 1996.
PINEL, Phillipe.

Tratado médico-filosófico sobre a alienação mental ou a mania. Porto Alegre: EdUFRGS. 2007.

PINHEIRO FILHO, Fernando Antonio;

MACHADO, Maíra Rocha.

Crime e castigo: a polêmica entre Gabriel Tarde e Émile Durkheim Novos Estudos, São Paulo, n.71, p.51-74. (Republicação do texto original de Gabriel Tarde, "Criminalidade e saúde social", publicado originalmente na Revue Philosophique de la France et de l'Étranger, Paris, 1895). 2005.

PRICHARD, James Cowles.

A treatise on insanity and other disorders affecting the mind. London: Sherwood, Gilbert and Piper. 1835.

RAFTER, Nicole Hahn.

Creating born criminals. Chicago: University of Illinois Press. 1997.

ROBERTSON, Phyllis K.

The historical effects of depathologizing homosexuality on the practice of counseling. The Family Journal, Thousand Oaks, v.12, n.163, p.163-169. 2004.

RUTTER, Michael.

What is the meaning and utility of the psychopathy concept? Journal of Abnormal Child Psychology, Berlin, v.33, n.4, p.499-503. 2005.

SCHNEIDER, Kurt.

Las personalidades psicopaticas. Madrid: Morata. 1968.

SILVA, Silvio Fernandes da.

Crescimento da violência urbana: as grandes cidades estão diante de uma epidemia social? Divulgação em Saúde para Debate, Rio de Janeiro, v.30, p.10-14. 2004.

SPENCER, Herbert.

The principles of sociology. Tome 1. London: Williams and Norgate. 1877.

STRAND, Michael.

Where do classifications come from? The DSMIII, the transformation of American psychiatry, and the problem of origins in the sociology of knowledge. Theory and Society, Berlin, v.40, n.3, p.273-313. 2011.

TARDE, Gabriel.

As multidões e as seitas criminosas. In: Tarde, Gabriel. A opinião e as massas. São Paulo: Martins Fontes. 1992.

TARDE, Gabriel.

Les lois de l'imitation. Paris: Felix Alcan. 1890.

VASSILEVA, Jasmin.

Psychopathy versus psychopathies in classifying criminal offenders. Legal and Criminological Psychology, Hoboken, v.10, n.1, p.27-43. 2005. 
VIANA, Milena de Barros.

Mudanças nos conceitos de ansiedade nos séculos XIX e XX: da Angstneurose ao DSM-IV. Tese (Doutorado) - Programa de Pós-graduação em Filosofia, Universidade Federal de São Carlos, São Carlos. 2010.

VIEN, Anh; BEECH, Anthony.

Psychopathy: theory, measurement, and treatment. Trauma, Violence \& Abuse, Thousand Oaks, v.7, n.3, p.155-174. 2006.

WALTERS, Glenn D.

The trouble with psychopathy as a general theory of crime. International Journal of Offender
Therapy and Comparative Criminology, Thousand Oaks, v.48, n.2, p.133-148. 2004.

WIDIGER, Thomas.

Classification and diagnosis: historical development and contemporary issues. In: Maddux, James E.; Winstead, Barbara A. (Ed.). Psychopathology: foundations for a contemporary understanding. Mahwah: Lawrence Erlbaum. 2004.

WORMS, René.

Organisme et société. Paris: V.Giard et E.Brière. 1896. 